\title{
Cystic Prostatic Carcinoma - A Clinical Case and Literature Review
}

\author{
Sergey $V$ Popov $\mathbb{D}^{1-3}$ \\ Igor N Orlov iD ${ }^{1,4}$ \\ Daria Yu Chernysheva (D) \\ Sergey M Malevich (iD) \\ 'Urology Department, St. Luke's Clinical \\ Hospital, Saint-Petersburg, Russia; \\ ${ }^{2}$ Urology Department, Military Medical \\ Academy Named After S.M. Kirova, \\ Saint-Petersburg, Russia; ${ }^{3}$ Hospital \\ Surgery Department, Saint-Petersburg \\ State University, Saint-Petersburg, Russia; \\ ${ }^{4}$ Urology Department, North-Western \\ State Medical University Named After I.I. \\ Mechnikov, Saint-Petersburg, Russia
}

\begin{abstract}
Cystic formations in the prostate are quite common, but the vast majority are benign. The cystic form of prostate adenocarcinoma can present unexpected symptoms, and management can be difficult because of the local advanced stage of the disease. A unique feature of this case is the surgical local cancer treatment. In this clinical case, we describe the literature surrounding this rare form of neoplasm. We present a clinical case of a rare form of prostate cancer in a 71-year-old male who was admitted to ER with acute urinary retention. A huge obstructing prostatic cyst was revealed. After successful trial-without-catheter, the patient underwent transperineal cyst draining and this restored urination. PSAt was increased up to $55 \mathrm{ng} / \mathrm{mL}$. The cystic wall biopsy revealed adenocarcinoma with a Gleason score of 8 $(4+4)$ (Gleason Group IV), and distant metastasis was noticed with PSMA PET/CT. The patient started androgen deprivation therapy (ADT) with excellent PSA dynamics in three months. Because of lower urinary tract symptoms, he needed local treatment and underwent radical prostatectomy. A three-month follow-up demonstrated a common post-operative period, mild stress incontinence, and PSAt $0.004 \mathrm{ng} / \mathrm{mL}$. Cystic prostatic carcinoma can manifest as urinary retention and be mistakenly taken for a benign obstructing prostate cyst. Despite the locally advanced tumor, it can be successfully treated locally in highly selected patients.
\end{abstract}

Keywords: prostate cancer, cystic adenocarcinoma, urinary obstruction

\section{Introduction}

Large cystic formations in the male pelvic organs are not common. ${ }^{1}$ Most prostate cysts are benign and may be congenital or acquired. ${ }^{2,3}$ Congenital cysts are usually related to maldevelopment of the Mullerian or Wolffian ducts, whereas retention cysts or prostate abscesses represent acquired ones. ${ }^{4}$ Malignant cystic formations of the prostate divide into papillary cystadenocarcinomas, mixed transitional cell adenocarcinoma, and adenoid cystic carcinoma. It should also be noted that multicystic adenocarcinoma of the prostate is more common than a cystic, solid one. ${ }^{5}$ Here, we present a patient with cystic degeneration of prostate adenocarcinoma, manifested by acute urinary retention and decreased renal function of postrenal genesis. A unique feature of this case is the surgical local cancer treatment.

\section{Case Presentation}

A 71-year-old man was admitted to the hospital ER with complaints of a lack of urination. The ultrasound revealed that the bladder contained over $800 \mathrm{~mL}$ of urine. A urethral catheter was inserted, and light clear urine of $870 \mathrm{~mL}$ was released. When asked about his complaints, he said he had been concerned for six months
Correspondence: Daria Yu Chernysheva
Urology Department, St. Luke's Clinical Hospital, Chugunnaya Street 46, SaintPetersburg, 194044, Russia

Tel +79218738560

Fax +7812576 II 55

Email Daria.chern@gmail.com 
about a weak urine stream, a feeling of incomplete bladder emptying, and the need to strain to start urinating. However, he had not sought medical help or seen a urologist for about five years. His past medical history was uneventful.

A digital rectal examination revealed a moderately enlarged prostate with a compaction in the left lobe, while the prostate surface was soft and elastic. Transrectal ultrasound (TRUS) revealed a volumetric fluid formation with thickened walls on the posterior prostate surface and a suspension of about $135 \mathrm{~mL}$ (Figure 1). Bilateral hydronephrosis was also noticed.

A laboratory clinical minimum revealed increased prostate-specific antigen (up to $55 \mathrm{ng} / \mathrm{mL}$ ), creatinine $(515.1 \mu \mathrm{mol} / \mathrm{L})$, and blood urea $(34.5 \mathrm{mmol} / \mathrm{L})$. Based on prostate-specific antigen (PSA) results, the primary diagnosis was "Prostate cancer. Acute urinary retention. Postrenal acute kidney injury."

After catheterization, natural urination was restored while taking the alpha-blocker tamsulosin $0.4 \mathrm{mg}$. Uroflowmetry showed an obstructive type of curve with Qmax at $3.7 \mathrm{~mL} / \mathrm{sec}$, Qav at $1.3 \mathrm{~mL} / \mathrm{sec}$, and $230 \mathrm{~mL}$ of residual urine. Bilateral hydronephrosis decreased significantly, creatinine dropped to $237.4 \mu \mathrm{mol} / \mathrm{L}$.

For diagnosis specification and before the proposed prostate biopsy, the patient underwent prostate MRI. It revealed a cystic solid tumor of the lower third of the prostate, with periprostatic tissue infiltration. The tumor was intimately adjacent to the anterior rectal wall (Figure 2).

To eliminate infravesical obstruction and histological diagnosis verification, the patient underwent TRUS-guided perineal puncture of the fluid formation and biopsy of the cyst and prostate wall, using an $18 \mathrm{G}$ biopsy needle. The transperineal approach was chosen to reduce bacterial load during the procedure, as a large cystic cavity may be

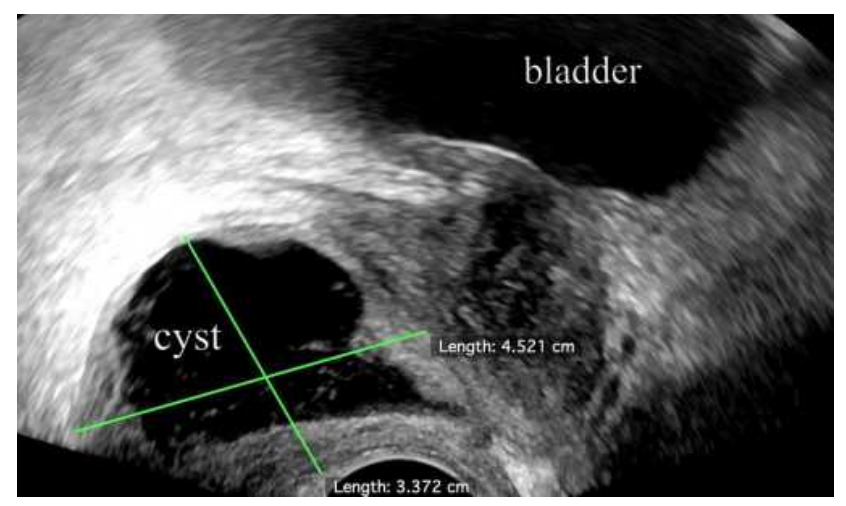

Figure I B-mode transrectal ultrasound revealed a huge prostatic cyst. poorly penetrated by antibiotics. As antibiotic prophylaxis, $2 \mathrm{~g}$ of Ceftriaxone was administered once intravenously.

The puncture yielded $140 \mathrm{~mL}$ of hemorrhagic discharge (Figure 3). The cytological examination of the fluid did not reveal atypical cells. In addition, one column of tissue containing the wall and bottom of the cystic formation was taken. A morphological study concluded as follows: adenocarcinoma with a Gleason score of 8 (4+4) (Gleason Group IV).

Repeated uroflowmetry showed an improved urination rate (Qmax $8.1 \mathrm{~mL} / \mathrm{sec}$, Qav $4.3 \mathrm{~mL} / \mathrm{sec}$ ) and $90 \mathrm{~mL}$ of residual urine. Creatinine was $124.9 \mu \mathrm{mol} / \mathrm{L}$.

For disease staging, PET-CT of the whole body was performed with ${ }^{68} \mathrm{Ga}$-PSMA, revealing a secondary lesion of the Th2 vertebra (SUV=9.6) (Figure 4).

The patient's final diagnosis was as follows: "Prostate cancer T3aNxM1b. Gleason 8 (4+4) (Gleason Grade Group IV). Oligometastatic prostate cancer, high-risk group". Due to local spread, the patient started therapy with a gonadotropin-releasing hormone analogue goserelin at $3.6 \mathrm{mg}$ once 10 . A month later, laboratory blood parameters were monitored: PSAt $-4.6 \mathrm{ng} / \mathrm{mL}$, creatinine $-118 \mu \mathrm{mol} / \mathrm{L}$, urea $-12.6 \mathrm{mmol} / \mathrm{L}$. Based on the diagnostic findings, it was decided to prolong the ADT with goserelin $10.8 \mathrm{mg}$ every 12 weeks. The patient tolerated the treatment uneventfully.

In a three-month period, PSAt dropped to 0.14 , and the patient insisted on radical treatment because of increasing lower urinary tract symptoms (LUTS). There were no signs of disease progression - the size of vertebral metastasis decreased by $40 \%$. Despite the EAU guidelines, he rejected the radiotherapy and was referred to radical prostatectomy. The surgery was uneventful. The macro- and microscopic morphology is shown in Figures 5 and 6.

The three-month follow-up demonstrated no specific complications but mild stress incontinence. The PSAt was $0.004 \mathrm{ng} / \mathrm{mL}$. Follow-up will be prolonged.

The patient's perspective: I am not the type of person who runs to the doctor every time he has an illness. That's why I avoided visiting my urologists for 3-4 years despite having problems with my urination. Difficulties with urination increased during this time, but generally, I felt quite healthy: I continued working and doing sport (Skandic walking). The day I could not pee was the scariest moment of my life. Not only because of the pain, but also because of the fact that the doctors in ER suspected that I might have cancer. After I had received the confirming test results, I knew I was going to put up a fight. All the following procedures (cyst draining, drug injection) were quite comfortable, and I got through them relatively easily. 


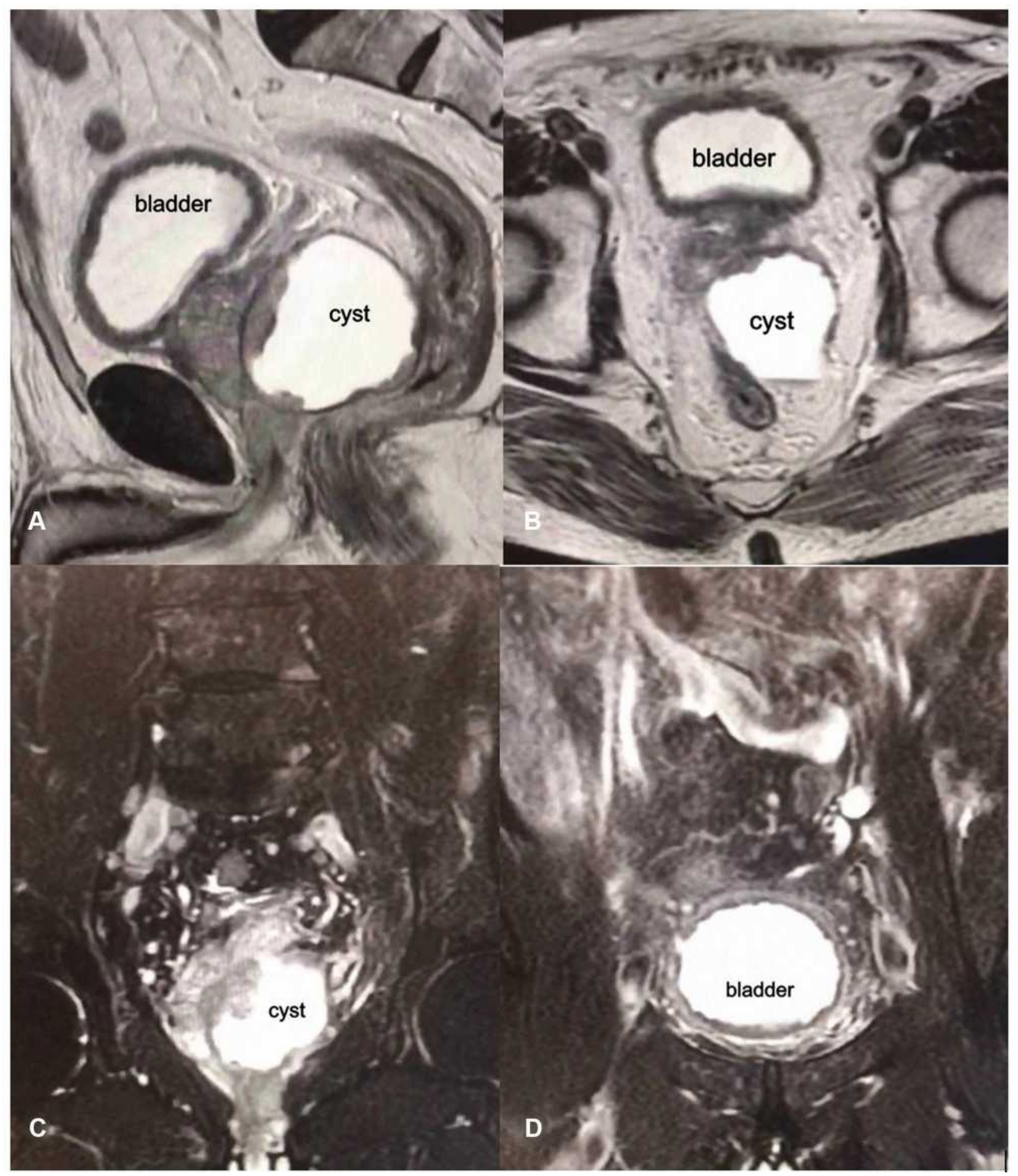

Figure 2 MRI revealed a cystic solid neoplasm of the left prostatic lobe adjacent to the anterior rectal wall. (A) T2 Sag plane (B) T2 Ax plane (C and D) DCE Sag plane.

The next tough moment was the discussion about my future treatment plan. I was not ready to give up and wanted this thing to be taken out of me despite all those worldwide recommendations and scientific protocols. After the surgery, I felt so relieved.

\section{Discussion and Conclusion}

An analysis of literature from 1991 to 2020 has identified ten clinical cases of cystic adenocarcinoma with histologically verified diagnosis (Table 1). Patient age ranged from 62 to 81 years, and most of them showed significantly 


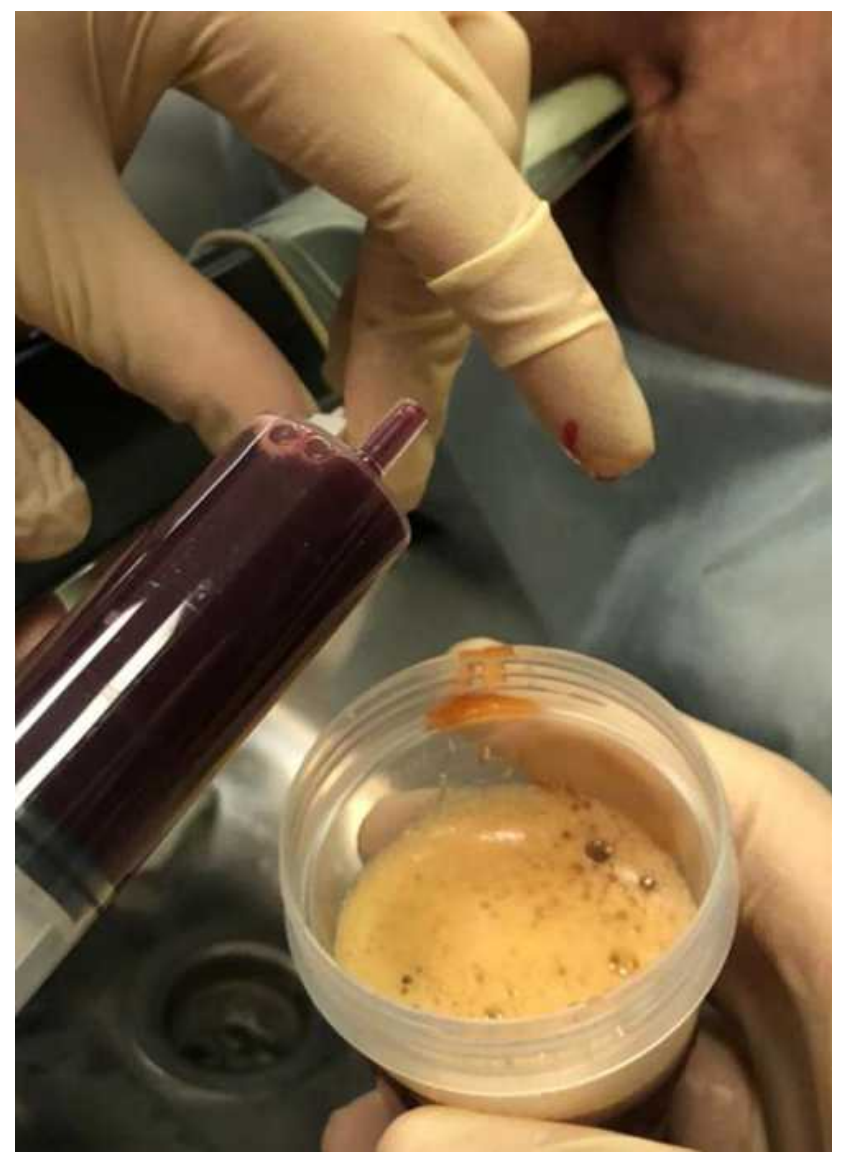

Figure 3 Perineal US-guided puncture of the cyst resulted in $140 \mathrm{~mL}$ of hemorrhagic discharge. One transperineal biopsy shot of the cystic wall was also taken.

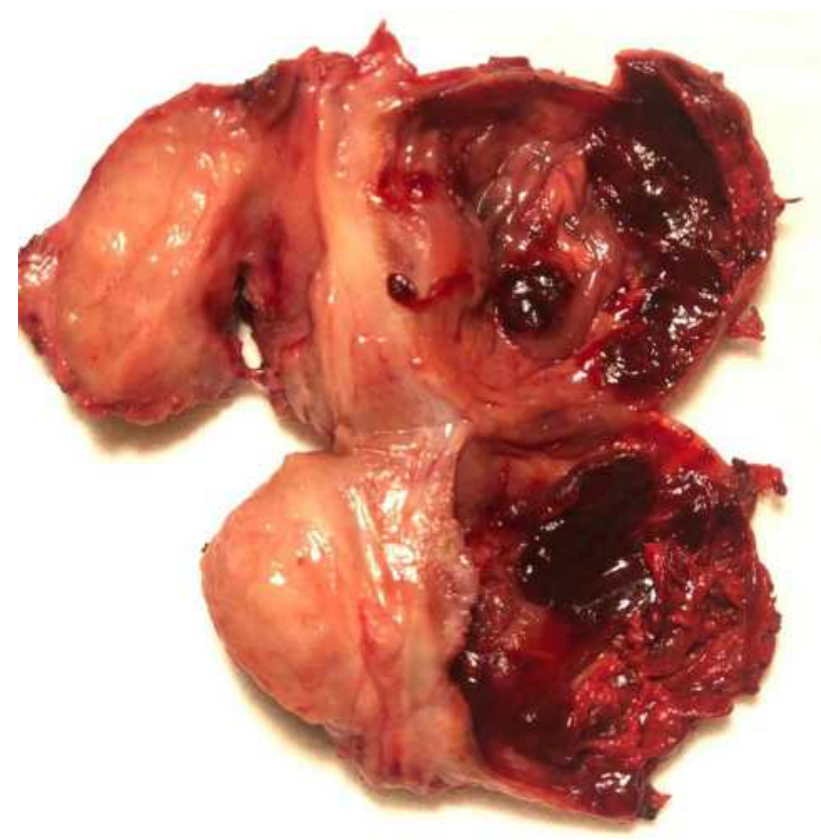

Figure 5 Macroscopic appearance of the prostate showed that almost the entire left lobe degenerated with cyst formation.

increased PSA volume. Cystic adenocarcinoma is mostly manifested by the symptoms of infravesical obstruction, both gradually increasing and suddenly occurring. As a rule, acute urinary retention was caused by tumors with a cystic component of $6 \mathrm{~cm}$ in the largest size. Clinical

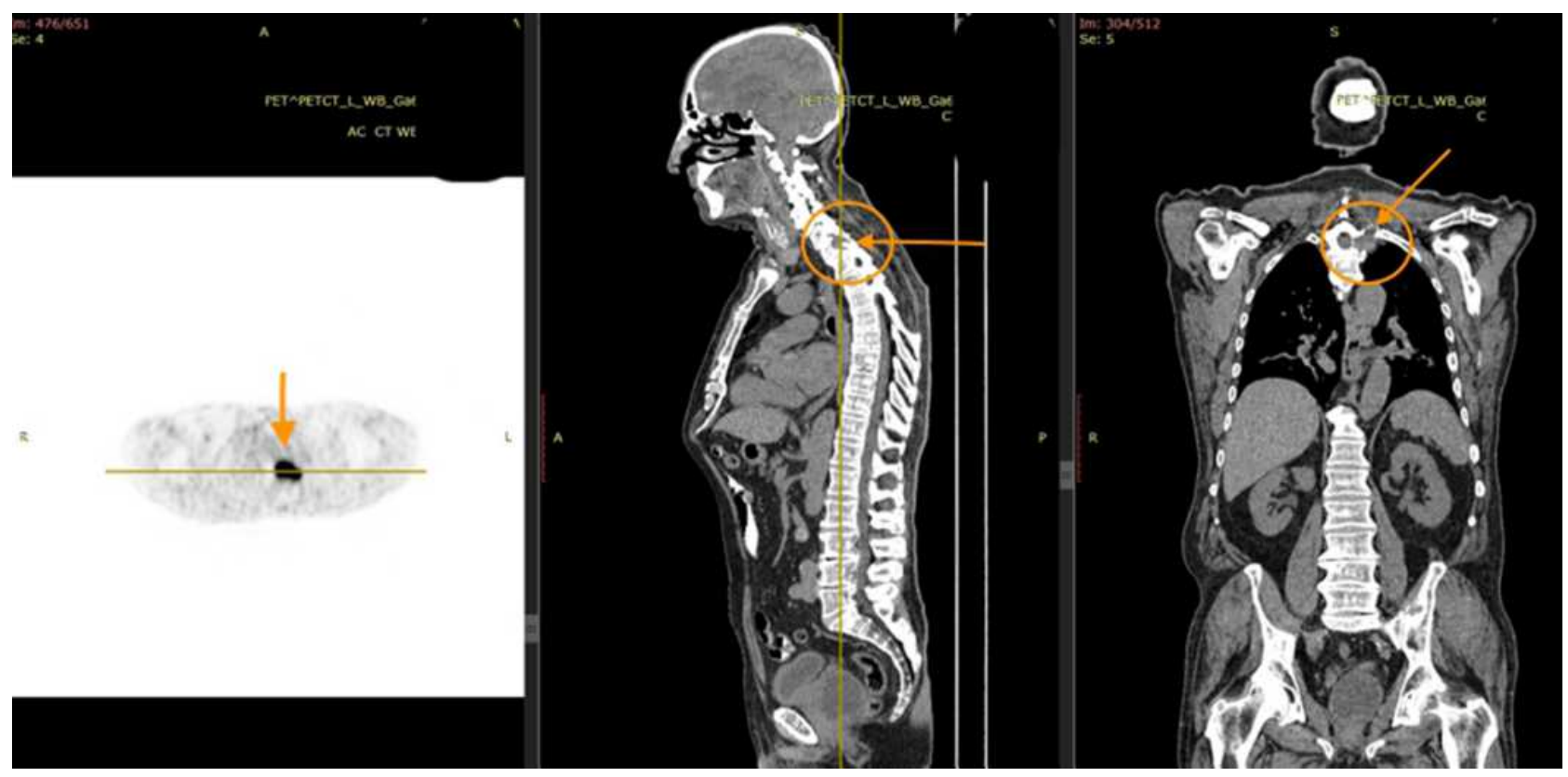

Figure 4 PSMA PET/CT scan revealed a distant metastasis in Th2. 


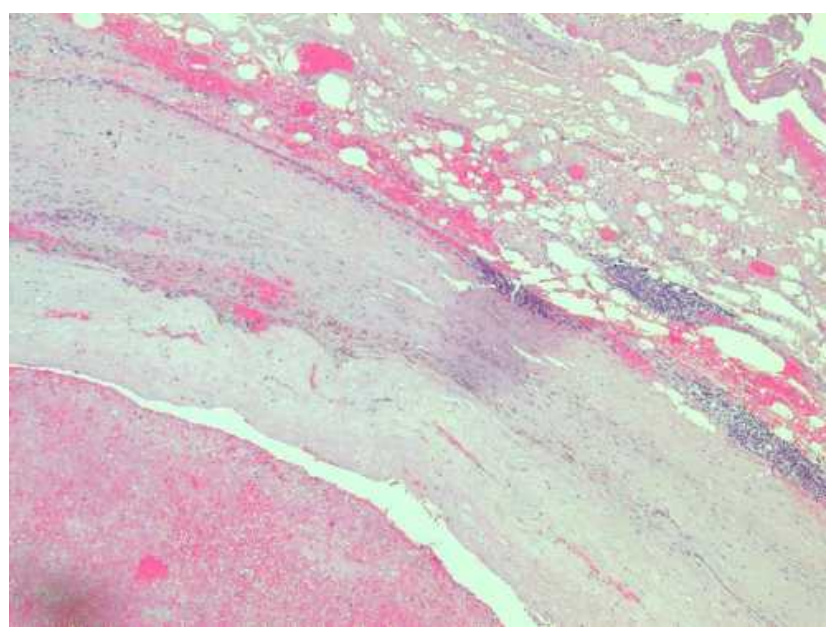

Figure 6 Microscopic appearance of the cyst wall and the prostate adenocarcinoma, with hematoxylin and eosin staining, $x 100$.

data in our study were similar to those in foreign publications.

Radiologists need to be familiar with such forms of the disease and be able to perform differential diagnoses. Describing a diagnostic study conclusion involves noting the shape and architectonics of the cystic formation walls and the nature of the fluid content. ${ }^{6}$ In cystic prostate lesions, the presence of a hemorrhagic component must suggest that the process is malignant. ${ }^{10}$

To confirm the diagnosis, it is necessary to perform a biopsy with material sampling from the dense areas of the cystic formation and prostate tissue. In the presented clinical case, as well as in others described, prostate adenocarcinoma was detected. The pathogenesis of cystic adenocarcinoma has not been fully studied.

Table I Average Readings for I I Cases of Cystic Carcinoma of the Prostate

\begin{tabular}{|l|l|}
\hline & Literature Review (10 Cases) ${ }^{2,5-13}$ \\
\hline Age (years) & $69.6(62-8 \mathrm{I})$ \\
\hline Primary complaints & $\begin{array}{l}\text { - LUTS - 27\% } \\
\text { - AUR - 27\% } \\
\text { - Suspicion at DRE - 9\% } \\
\text { - Orchoepididymitis - 9\% } \\
\text { - Hematuria - 9\% } \\
\text { - Increased PSA - 9\% }\end{array}$ \\
\hline PSA (ng/mL) & $243.2(2.9-1324)$ \\
\hline Formation diameter & $6.8(1.5-15)$ \\
\hline
\end{tabular}

Abbreviations: LUTS, lower urinary tract symptoms; AUR, acute urinary retention; DRE, digital rectal examination; PSA, prostate specific antigen.
Two theories on the onset of the cystic component have been put forward. The first theory suggested pseudocystic formation development from the local necrosis area or bleeding in prostate carcinoma. According to the second hypothesis, the cause was malignancy of an ordinary prostate cyst. ${ }^{10}$ A Japanese study of cystic prostate cancer found that cystic adenocarcinoma usually developed from pseudocysts with bleeding and only in $17 \%$ of cases due to malignancy of ordinary prostate cysts. ${ }^{14}$

Disease staging is of great importance in determining further tactics of treating patients with this pathology. Treatment strategy for cystic carcinoma includes all types of care typical of prostate cancer, as well as hormonal therapy, cyst draining surgery and radiotherapy. In the presented case, given secondary changes in the Th2 vertebra, hormonal therapy was initial. After reinspection of the patient three-months later, concerning the positive dynamics and increasing LUTS, the patient was offered surgical treatment. After surgery PSAt dropped and in three-months was $0.004 \mathrm{ng} / \mathrm{mL}$. Concerning the patient's decision on surgical treatment, we believe that results of CHAARTED trial (showing a significant overall survival benefit by the addition of prostate radiotherapy to ADT in low volume metastatic group) could be extrapolated to any local treatment, including radical prostatectomy. We hope that surgery will help us to prolong the time to PSA progression.

The follow-ups in the previous ten cases revealed significantly lower blood PSA and smaller neoplasms. However, the follow-up period was not long term and did not fully assess disease dynamics on treatment.

Cystic adenocarcinoma is a very rare disease requiring methodical diagnosis, differential diagnosis, and treatment. Further research on its clinical cases would allow a study of pathogenesis and determine recommendations for optimal scope of diagnosis and treatment.

\section{Ethics}

The local ethics committee approved the treatment strategy. Institutional approval was not required to publish the case details. Written informed consent was obtained from the patient for publication of this case report and any accompanying images.

\section{Acknowledgments}

We thank Dr Peremyshlenko Alexey for performing the morphology studies and Dr Neradovskiy Vyacheslav and Dr Sushina Irina for the technical help. 


\section{Author contributions}

DYC and SMM were involved in the protocol design, surgical interventions, data collection, and manuscript writing. INO and SVP were involved in the protocol development and manuscript editing. All authors made substantial contributions to conception and design, acquisition of data, or analysis and interpretation of data; took part in drafting the article or revising it critically; all authors read and approved the final manuscript, agreed to submit to the current journal; gave final approval of the version to be published; and agreed to be accountable for all aspects of the work.

\section{Funding}

No funding was used for this article.

\section{Disclosure}

The authors declare that they have no competing interests.

\section{References}

1. Lim DJ, Hayden RT, Murad T, Nemcek AA Jr, Dalton DP. Multilocular prostatic cystadenoma presenting as a large complex pelvic cystic mass. J Urol. 1993;149:856-859.

2. Tsuji H, Hashimoto K, Katoh Y, Iguchi M. Prostatic cancer with huge cystic degeneration. Urol Int. 1999;62:48-50. doi:10.1159/000030356
3. Hamper UM, Epstein JI, Sheth S, Walsh PC, Sanders RC. Cystic lesions of the prostate gland. A sonographicpathologic correlation. J Ultrasound Med. 1990;9:395-402. doi:10.7863/jum.1990.9.7.395

4. Curran S, Akin O, Agildere AM, Zhang J, Hricak H, Rademaker J. Endorectal MRI of prostatic and periprostatic cystic lesions and their mimics. AJR Am J Roentgenol. 2007;188:1373-1379. doi:10.2214/ AJR.06.0759

5. Nerli RB, Patil R, Sharma V, Ghagane SC, Hiremath MB. Cystic prostatic carcinoma. Clin Oncol. 2016;1:1154.

6. Llewellyn CH, Holthaus LH. Cystic carcinoma of the prostate: findings on transrectal sonography. AJR Am J Roentgenol. 1991;157:785-786. doi:10.2214/ajr.157.4.1892036

7. Parr NJ, Hawkyard SJ. Carcinoma of the prostate presenting as cystic pelvic mass. Br J Urol. 1994;73:213-214. doi:10.1111/j.1464410X.1994.tb07500.x

8. Agha AH, Bane BL, Culkin DJ. Cystic carcinoma of the prostate. J Ultrasound Med. 1996;15:75-77. doi:10.7863/jum.1996.15.1.75

9. Khorsandi M. Cystic prostatic carcinoma. J Urol. 2002;168:2542. doi:10.1016/S0022-5347(05)64193-6

10. Chang YH, Chuang CK, Ng KF, Liao SK. Coexistence of a hemorrhagic cyst and carcinoma in the prostate gland. Chang Gung Med J. 2005;28:264-267.

11. Chen CH, Lin YH, Tzai TS, Tsai YS. Prostate cancer associated with hemorrhagic cyst: findings on transrectal Doppler sonography. J Med Ultrasound. 2008;16:292-295. doi:10.1016/S0929-6441(09)60007-2

12. Ng KL, Sathiyananthan JR, Dublin N, Razack AH, Lee G. Cystic adenocarcinoma of prostate: a case report. J Health Transl Med. 2011;14:21-22. doi:10.22452/jummec.vol14no1.4

13. Fung KH, Tsang WK, Kwok CH, Lee WT, Tang KW. Cystic prostatic carcinoma: case report and literature review. Hong Kong Med J. 2020;26(1):66-69. doi:10.12809/hkmj197984

14. Kim SC, Fujimoto K, Matsumoto Y, et al. A case of prostate cancer with cyst formation. Hinyokika Kiyo. 2001;47:653-656.
Research and Reports in Urology

\section{Publish your work in this journal}

Research and Reports in Urology is an international, peer-reviewed, open access journal publishing original research, reports, editorials, reviews and commentaries on all aspects of adult and pediatric urology in the clinic and laboratory including the following topics: Pathology, pathophysiology of urological disease; Investigation and treatment of urological disease; Pharmacology of drugs used for the treatment of urological disease. The manuscript management system is completely online and includes a very quick and fair peer-review system, which is all easy to use. Visit http://www.dovepress.com/ testimonials.php to read real quotes from published authors. 